\title{
Electronic Collaboration Across Cultures in a Web-based Project for English Writing Instruction*
}

\author{
George C.K. Jor
}

\begin{abstract}
The paper highlights the importance of experimentation and an innovative approach to English language writing instruction with the help of information communication technology (ICT or IT). First, it describes the local situation of English language teaching at The Chinese University of Hong Kong (CUHK). Then, it summarizes the development of IT proficiency and student-led collaborative learning groups at CUHK. Third, it reports on an international Web-based writing project involving six collaborating schools in different parts of the world including China, the United States, Indonesia, and Hong Kong in the year 1999-2000. In the report, the author-presenter will share with the audience a new ELT course development titled "English Online: Writing on the Web." He will explain the course objectives, the background of participating classes, the Web Course Tools (WebCT), the design of the project, the evaluation of course effectiveness and the outcome of the new curricular initiative. Finally, the paper presents a summary of a practical guide to electronic collaboration and some of the lessons the writer has learnt in five years' experience of participant-observation in English teaching practice using the Web.
\end{abstract}

Keywords: collaboration, IT, web course tools, teaching, English online, course development.

\section{The importance of experimentation and innovation in education}

The Internet is transforming the way we live, think, talk, communicate, and learn. The Newsweek magazine published a special report titled "The Dawn of E-life" on October 11, 1999. It is an interesting report on the impacts of the digital revolution on various aspects of our lives (Newsweek, October 11, 1999, 33-47). It is not about the future - it's about what is happening here and now, and about how we teach and learn.

Universities are now under tremendous pressure to change. The forces of change go beyond colleges and universities themselves. These powerful forces include globalization and the free economy; the financial imperatives - fear of cuts in public funding, societal needs, and technology drivers. The buzzwords today are "knowledge-based economy," "market economy," "IT" and "lifelong learning." Some things that go well beyond pedagogy are at stake. "Can colleges and universities survive in the information age?" James Duderstadt questioned the traditional modes of education (Duderstadt, 1999, pp.1-27). In one radical example, Peter Drucker was quoted as saying "Within thirty years, universities will become relics" (Duderstadt, 1999, pp.1-27). There will be more and more "just in time," "just in case" and "just for you" experiments of education services for a new, ever-increasing group of lifelong learners - working adults. Closely

\footnotetext{
Paper presented at the SOUTHEAST ASIAN MINISTERS OF EDUCATION ORGANIZATION (SEAMO) Regional Language Centre (RELC), 35th RELC International Seminar, Singapore, 17 - 19 April 2000. Theme of the Seminar: LANGUAGE CURRICULUM \& INSTRUCTION IN MULTICULTURAL SOCIETIES.
} 
studying the impact of technology on the "ivory towers" in North America, Brian Lewis and his colleagues highlight the immanence of change and the need for policy planning in technology and education. Their book Tower under siege: technology, policy and education will be published by McGill-Queens in a few months' time. Both Duderstadt and Lewis find it hard to underestimate the importance of experimentation and innovation in tertiary education in the 21st Century (Lewis, 2000).

In the field of English language instruction, the rise of the new technologies has ushered in the age of collaboration. The Internet and the World Wide Web have created a global English learning environment with new needs and new challenges. There is the challenge of a paradigm shift from faculty-centered instruction to learner-centered initiatives. A teacher's role is shifted from a content provider to a learning facilitator (Sandholtz, 1997). There is a need to recognize new learner needs and requirements; a challenge to respond to increased competition with new teaching services; a challenge to respond to decreased public funding with new efficiencies, to seize new opportunities and develop strategic planning, and a need to nurture partnership and strategic alliance with other schools and organizations. In short, collaborative learning in a digital world is here and now. Our traditional mode of education is no longer enough. Reform-minded educators have called for experimentation and innovation. Some have experimented with and argued for the case of the constructivist classrooms (Brooks and Brooks, 1993). Some pioneering practitioners, like Mark Warschauer of the University of Hawaii, have published significant works outlining the importance of e-mail (Warschauer, 1995) and the Internet for English language teaching (Warschauer, 2000).

\section{English Language Teaching at CUHK}

At The Chinese University of Hong Kong, the curriculum is basically a three year one. The English Language Teaching Unit (ELTU) offers a variety of elective courses to enable undergraduates to improve their English language skills and develop more confidence in communicating in the language. There are three categories of course offerings:

(1) foundational courses that focus on developing a particular English language ability like listening, speaking, writing, or reading;

(2) integrated courses that focus on a specific topic like current affairs, visual media, nature, culture, or the environment; and

(3) integrated courses that focus on English use in a specialized area such as technical communications or business communications (The Chinese University of Hong Kong Student Handbook 1999-2000, p.58).

Since 1998, the ELTU has collaborated with the Faculty of Education to offer a fouryear full time bachelor of education (Language Education) programme. The role of the ELTU is to develop students' language competency to ensure that they attain a high level of competence and be able to function effectively in English in their studies.

In the year 1999-2000, the ELTU offers 19 courses. In the fall term, 1999, there are 103 classes with a total of 1784 students. In the spring term, 2000, there is a slight increase to 111 classes with a total of 1985 students. Of the nineteen courses, ten have used the Internet and the Web in various degrees to assist instruction. That means more than half of the courses have used different kinds of technologies to a certain extent. The kinds of uses range from simple e-mail contact with students to fully 
integrated course management tools like WebCT, WebBoard and electronic marking. $53 \%$ of the courses are involved in experimenting, in one way or another, with teaching English using new technologies.

We seek to find more efficient and effective ways to meet our students' needs in the age of information. Our biggest challenge has been the 25\% increase in teaching load since 1998 and the lack of time for curriculum reform. We are now required to teach five classes per semester or ten classes per year. The maximum class size is 22 students per class. Apart from teaching students, marking papers, administrative duties and service to the college, there is little time left for us to think about course development, which is usually not recognized. There seems to be an imbalance in rewards given research versus those accorded teaching. Starting from summer 1999, part of the faculties is required to teach summer courses as well. Yet, we are not giving up. Some of us have tried to find time to experiment with new courses that might make a difference for our students. We are developing new courses and we welcome opportunities of cooperation and collaboration with like-minded colleagues and agencies locally and internationally.

\section{Development of IT proficiency and student-led collaborative learning groups at CUHK}

At CUHK, the campus backbone network was put in place in 1992. It is a high-speed information infrastructure for teaching, learning, library and service. All the students and faculties are provided with an e-mail account free of charge. Since 1998, a web server account called "ihome" has been made available to all members of the university without their applying for it. The disk quota for each user is $15 \mathrm{MB}$. All members have free Internet access on campus 24 hours a day, and seven days a week.

Recently, two major developments on IT for teaching and learning have emerged. Both are related to electronic literacies - the abilities to read and write with electronic media. One is more related to the faculties in particular and the other, to the first year undergraduates.

For teachers, web-assisted instruction was introduced in 1998. According to the statistics of the Computer Services Centre, there are 131 courses using WebCT with a total of 7072 users as of March 30, 2000. At the same time, there are 67 courses using the WebBoard with a total of 4401 users. A university-wide survey on the use of webassisted instruction is currently under way in March and April, 2000. There are no official figures yet. It is, however, possible to make an educated guess judging by the current number of undergraduate enrolment (including medical students). According to the Registry, there are 8930 undergraduates as of December 31, 1999. Comparing the Web statistics with the student enrolment, it is reasonable to say that web-assisted instruction is taking hold at CUHK and is flourishing. Teachers are facing everincreasing demands from students for new ways of teaching with new technologies.

For first year students at CUHK, there is now a new graduation requirement - an IT Proficiency Test.

"Applicable to undergraduate students admitted in 1999-2000 and thereafter, and to postgraduate students admitted in 2000-2001 and thereafter. All students are required to sit in an IT Proficiency Test in their first year of study. Students who fail the Test will be required to attend a summer intensive course and sit the Test again in their second year. Any student who still does not pass the Test in the second year 
will be required to attend the summer intensive course again. Students will be barred from graduation if they do not pass the Test and have not attended the summer intensive course."

(Source of information: Student Information Technology Competence Test

URL: http://sitc.cuhk.edu.hk/intro.html\#test)

The challenge for students is more than just a pass in the IT Proficiency Test. It is about problem solving and lifelong learning. They must realize that what they have learnt will become obsolete very soon. They must learn how to learn and be their own teachers as they respond to the challenge of serving a changing society and a profoundly changed world.

\section{Student-led collaborative learning groups at CUHK}

Michael Bond, a psychology professor at CUHK, made a salient point in one of his public lectures. He quoted a report made to the Human Capital Initiative sponsored by the Social Science Research Foundation, "... to cope with rapid change over the next 25 years, Asian socieites must wean students from teacher-dependent learning and foster creative initiative in problem solving" (Bond, 1999).

The title of his lecture is tale-telling: "Using Student-Managed Task Groups To Enhance Learning" He advocates a strategy of using student-managed groups. The teacher assigns a number of sufficiently structured, course-related tasks which require consultation on procedures and an efficient division of labour for successful completion (Bond, 1999).

He takes into considerations the following factors: grading, feedback, membership and class presentation by groups. The grading is based on groups. Common fate falls on all assignments, thereby promoting cooperation and sensitization to the group process. The teacher can require members to assign one another grades based on individual contribution related to those components, and hence preventing free-riding (Bond, 1999).

The feedback provides process control. The group is required to give a progress report to the instructor in the mid-term. In the final assignment, the teacher can require each individual to give concrete, behavioural feedback to other members about his or her contribution and shortcomings in the group setting. This may be supplemented by individual goal-setting at the beginning of the term and compared with other's feedback.

There can be positive and negative feedback. Students learn to give negative feedback and offer an alternative. As Emerson said, "Every room has a door". It is important to learn how to frame the negative feedback. It is okay to fail, just keep trying until one succeeds. As Bob Dylan put it, "Nothing succeeds like failure." If a group is not happy with their performance, they can seek improvement. Bond observes that growth happens on the edge of dissatisfaction. Learning to give good advice and negative feedback can help students build social skills and sensitize them to social relationship and teamwork (Bond, 1999).

Membership of the group should not be too large. Bond suggests that the maximum number be six. The point is to facilitate scheduling meetings, to enable closer relationships and to ensure that enough work can be shared (Bond, 1999).

Class presentations by groups encourage team spirit and competition among groups. It enables the group to excel before other groups (Bond, 1999). It also encourages peer teaching and peer learning. 
Bond sums up the costs and payoffs of the collaborative student-led task group strategy at the end of his talk. It takes close monitoring of each group by the instructor. It may be brief, but regular. Occasionally, a student may complain against his or her group members for unfair treatment and it takes time to counsel the student. The course may earn a reputation of being "demanding" (Bond, 1999).

The payoffs of the collaborative task group strategy seem to offset the costs remarkably. The task group can be a substitute for tutorials saving the teacher lots of time in preparation and delivery. The marking time is reduced. The classroom becomes a more sociable setting and students cannot remain anonymous. The task group also trains for important, but often neglected "people skills." Bond reports that the strategy results in higher course evaluations and it leads to grading and developing a broader range of student talents (Bond, 1999).

\section{English Online: Writing on the Web}

Influenced by Bond's idea of collaborative task group strategy, English Online: Writing on the Web is a new course that aims to "paint with two brushes at the same time."1 It aims to integrate two desirable goals to meet new student needs in the age of information combining English writing instruction with IT skills. In other words, it is designed to help students develop electronic literacies - the abilities to read and write with electronic media in the digital world (Tyner, 1999, Warschauer, 2000). A major course component is the student-led task group in the form of a final project - a collaborative, international writing exchange across cultures in the format of a Web Fair.

\section{Course description}

The course is designed to help college students improve their English writing skills with the aid of information and communication technology. Specifically, it will focus on developing students' English proficiency, competence and confidence by integrating the writing process with the Web. It will show students how to do research efficiently, write a research paper and present information effectively. This course will integrate IT with thinking and writing. Course work will include writing a research paper, keeping electronic journals, critical uses of the Web and search engines, and joining electronic conferences. The course is suitable for students who feel comfortable with the idea of learning with computers and who want to strengthen their English writing skills with the help of Web-based instruction. WebCT, a course management tool, is used. There is also a course website at URL: http://humanum.arts.cuhk.edu.hk/ cmc/2002a/index.html

\section{Syllabus}

The overall structure is presented as follows:

Part I Introduction to the concept of electronic literacies, peer teaching-learning, and the process of writing.

Part II Strengthening writing skills by regular practice including 
- keeping electronic journals

- writing class work and giving peer feedback.

Part III Research techniques: collecting data from primary, secondary sources \& documenting sources. Group work.

Assignment 1: Collaborative hypertext project. (minimum 8 pages)

Assignment 2: Research report. (1200 words)

Part IV Integrating electronic communication skills with English writing proficiency by collecting and selecting better pieces for a writing portfolio and giving an oral presentation. Course Evaluation.

\section{Evaluation}

Assessment will be made by the teacher and fellow students based on a set of objective criteria agreed upon in the class and that requires mastery of the knowledge and skills practiced in the course.

\begin{tabular}{|l|c|l|}
\hline \multicolumn{1}{|c|}{ Learning } & Percentage & \multicolumn{1}{c|}{ Type of work } \\
\hline Journal writing & $20 \%$ & Keeping journals (individual work) \\
\hline Essay 1 & $10 \%$ & $\begin{array}{l}\text { Writing to express (individual work) } \\
\text { Class work A: Description and illustration }\end{array}$ \\
\hline Essay 2 & $10 \%$ & $\begin{array}{l}\text { Writing to inform (peer feedback) } \\
\text { Class work B: Comparison and contrast }\end{array}$ \\
\hline Essay 3 & $10 \%$ & $\begin{array}{l}\text { Writing to persuade (peer feedback) } \\
\text { Class work C: Argumentative essay }\end{array}$ \\
\hline Assignment 1 & $20 \%$ & $\begin{array}{l}\text { Writing home pages for the group project \& } \\
\text { publishing it on the Web (group work) }\end{array}$ \\
\hline Assignment 2 & $20 \%$ & $\begin{array}{l}\text { Writing a research report on your project } \\
\text { experience. (group work) } \\
\text { Integrating the report into your writing portfolio } \\
\text { (individual work) }\end{array}$ \\
\hline Oral Presentation & $10 \%$ & $\begin{array}{l}\text { Group project and portfolio presentation in a Web } \\
\text { Fair }\end{array}$ \\
\hline & $100 \%$ & Total \\
\hline
\end{tabular}

\section{Participating Schools and partnership in the electronic collaboration}

As part of the course requirements, students are required to do a final project involving a collaborative writing exchange across cultures. The course instructor teams up with overseas teachers and sets a number of sufficiently structured, writing tasks which require collaboration, partnership and contributions from different school teams for successful completion. It is a student-led task group activity that requires lots of exchanges by e-mail, asynchronous discussion on a Web-based bulletin board and synchronous real-time tele-conference such as chat room appointments and one interclass video conference.

In the fall term 1999, there are four collaborative schools involving seven teachers and 83 students. The students are divided into nine editorial teams. The schools are 
The Chinese University of Hong Kong, Soochow University, China, Pui Ching Middle School, and Bennett College, North Carolina. [2]

There is a central theme in the Collaborative Writing Project 1999. It is titled "Adjusting to the First Year." Students work in teams to compare their experiences or expectations of adjusting to the first year at college. Then they edit and publish selected parts of their writing on the WebCT tailor-made for the course.

In the spring term 2000, there are six collaborative schools involving ten teachers, three MA students and 143 undergraduates. The partnership includes The Chinese University of Hong, Governors State University, Petra Christian University of Indonesia, Soochow University of China, Pui Ching Middle School of Hong Kong, and Bennett College.[3]

The central theme for the Collaborative Writing Project 2000 is "Quality Life Education." Ten topic areas are chosen from the No.1 US best seller Tuesdays with Morrie (Albom, 1999) - love, work, money, community, family, marriage, culture, fear of aging, forgiveness and death. Students chose their own topic and writing exchange partners. Then they edit, select parts of their writing, rewrite them in hypertext and publish them on the Web.

Here is a table of the statistics of the international writing exchange project.

\begin{tabular}{|l|l|l|}
\hline \multicolumn{1}{|c|}{ Term } & \multicolumn{1}{|c|}{ Fall, 1999 } & \multicolumn{1}{c|}{ Spring, 2000 } \\
\hline No. of students involved & 83 & 147 \\
\hline No. of teachers involved & 7 & 10 \\
\hline No. and names of schools & 4 & 6 \\
& The Chinese & The Chinese University of Hong \\
& University of Hong & Kong, HKSAR \\
& Kong, HKSAR & Bennett College, North Carolina, \\
& Bennett College, & USA \\
& North Carolina & Pui Chi Middle School \\
& Pui Chi Middle & Suzhou University, China \\
& School & Petra Christian University, East \\
& Suzhou University,, & Java, Indonesia \\
& China & Governors State University, \\
& & Illinois, USA \\
\hline
\end{tabular}

\section{Course effectiveness measure}

To measure the effectiveness of the course "English Online: Writing on the Web," two types of methods are used - quantitative and qualitative methods.

The quantitative methods include a pre-course and post-course rating of students' writing samples by two English teachers who are experienced markers. Double marking is used to increase the objectivity and reliability of the measurement. A well-established 6-point marking scheme - TOEFL Test of Written English (TWE) - is used for scoring purposes. In addition, students also take a pre-course and post-course attitudinal test of their perception of the course objectives. It is a 48-item questionnaire on students' selfassessment of the course objectives with six major categories:

- Understanding the writing process

- Writing proficiency 
- Developing IT competency

- Computer ethics

- Developing communication abilities

- Developing teamwork

The qualitative methods include a portfolio assessment for individual students and a group project assessment of their collaborative writing exchange involving electronic collaboration across cultures and participation in a Web Fair.

\section{Findings and discussions}

\begin{tabular}{|c|c|c|c|c|c|c|}
\hline Writing Sample & \multicolumn{2}{|c|}{ Marker One } & \multicolumn{2}{c|}{ Marker Two } & \multicolumn{2}{c|}{ Average } \\
\hline & PRE & POST & PRE & POST & PRE & POST \\
\hline 1 & 2.5 & 5 & 2 & 5 & 2.25 & 5 \\
\hline 2 & 3 & 4 & 4 & 5 & 3.5 & 4.5 \\
\hline 3 & 4 & 4 & 5 & 4 & 4.5 & 4 \\
\hline 4 & 3 & 4 & 4 & 3 & 3.5 & 3.5 \\
\hline 5 & 4 & 5 & 5 & 5 & 4.5 & 5 \\
\hline 6 & 3 & 5 & 6 & 6 & 4.5 & 5.5 \\
\hline 7 & 4 & 5 & 6 & 5 & 5 & 5 \\
\hline 8 & 3 & 4 & 5 & 4 & 4 & 4 \\
\hline 9 & 4 & 6 & 6 & 5 & 5 & 5.5 \\
\hline 10 & 4 & 5 & 6 & 3 & 5 & 4 \\
\hline 11 & 3 & 5 & 4 & 4 & 3.5 & 4.5 \\
\hline 12 & 4 & 4 & 4 & 5 & 4 & 4.5 \\
\hline 13 & 3 & 3 & 6 & 4 & 4.5 & 3.5 \\
\hline 14 & 4.5 & 5.5 & 5 & 5 & 4.75 & 5.25 \\
\hline 15 & 4.5 & 5.5 & 3 & 5 & 3.75 & 5.25 \\
\hline 16 & 3 & 5 & 6 & 6 & 4.5 & 5.5 \\
\hline 17 & 6 & 6 & 6 & 6 & 6 & 6 \\
\hline
\end{tabular}

Total score of PRE (pre-course writing activity) $=73.75$ Average PRE $=4.338$

Total score of POST (post-course writing activity) $=80.5$ Average POST $=4.735$

Figure 1. A Table Showing the Double Marking Scores of Students' Writing Samples by Two Experienced Instructors According to the Standard of the Test of Written English (TWE) of TOEFL in the fall term, 1999.

The difference in terms of percentage of TWE Scores $=9.2 \%$ increase (In the spring term 2000, the difference is a $15.8 \%$ increase in the scores.)[5]

TWE Scoring Guide on a scale of 1 to 6

6 Demonstrates clear competence in writing on both the rhetorical and syntactic levels, though it may have occasional errors.

5 Demonstrates competence in writing on both the rhetorical and syntactic levels, though it may have occasional errors 
4 Demonstrates minimal competence in writing on both the rhetorical and syntactic levels.

3 Demonstrates some developing competence in writing, but it remains flawed on either the rhetorical and syntactic levels, or both.

2 Suggests incompetence in writing

1 Demonstrates incompetence in writing.

This is only a summary of the scoring guide. There is a detailed description of each category. Interested researchers are recommended to consult the Education Testing Service at Princeton for details of the marking scheme.

Self-assessment of ELT 2002 English Online

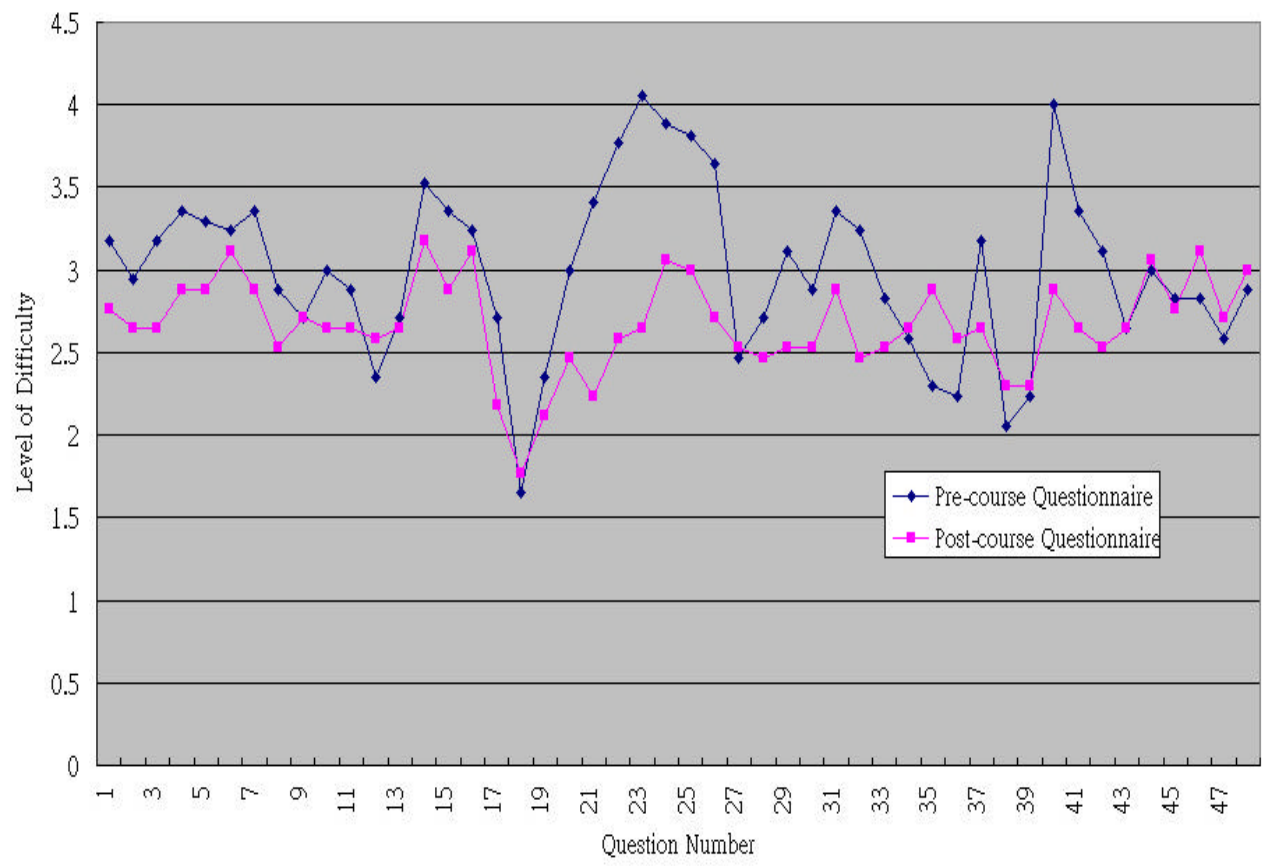

Figure 2. A Graphic Representation of Students' Self-assessment of the Course Objectives of English Online: Writing on the Web Showing the Changes Before and After in their Perceptions of the Level of Difficulty of 48 Aspects of the course. 


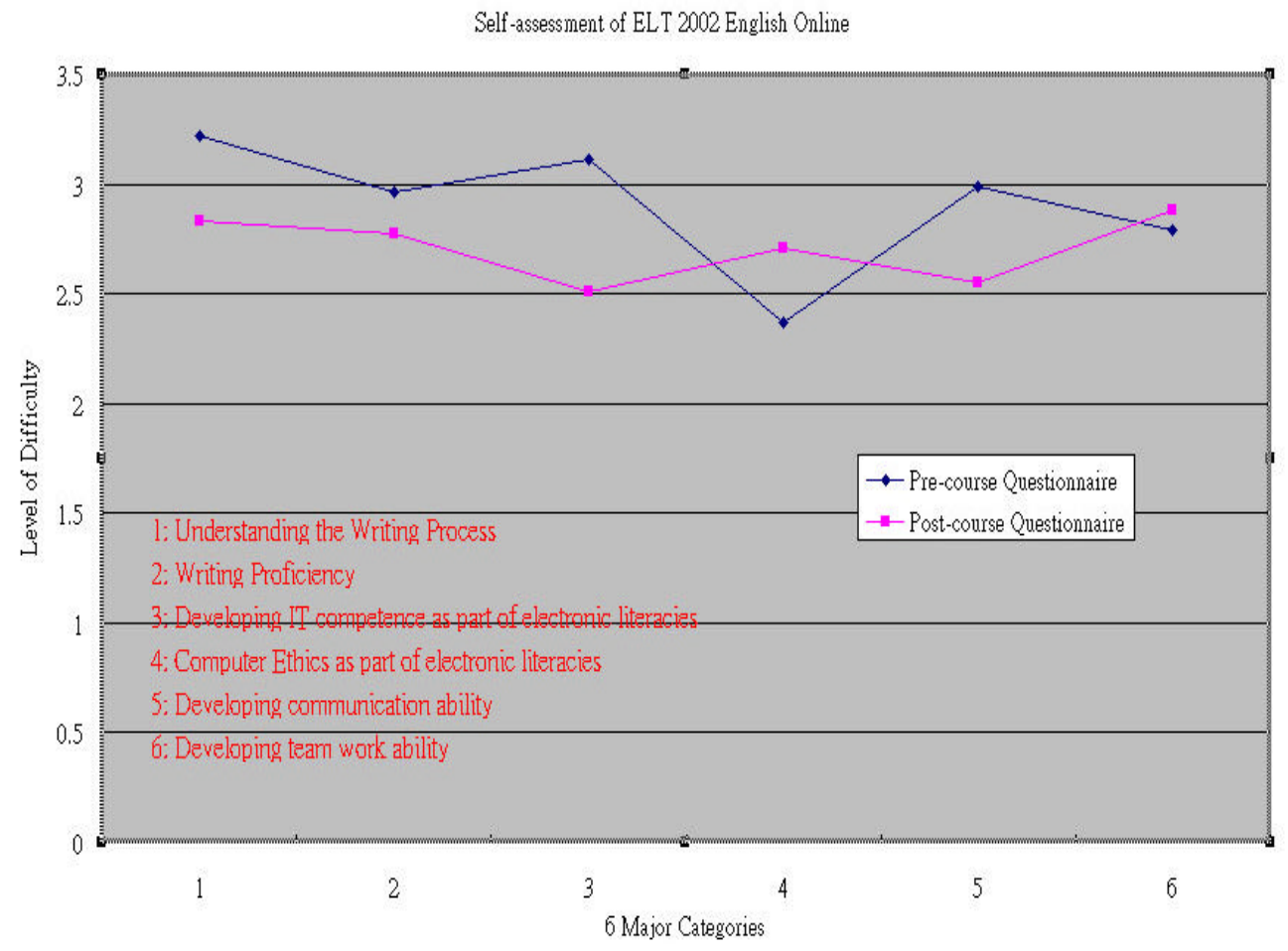

Figure 3. A Graphic Representation of Students' Self-assessment of the Course Objectives of English Online: Writing on the Web Showing the Changes Before and After in their Perceptions of the Level of Difficulty of 48 Aspects of the course in six clusters: 1 . Understanding the Writing Process, 2. Writing Proficiency, 3. Developing IT Competence, 4. Computer Ethics, 5. Developing Communication Abilities, and 6. Developing Teamwork.

\section{Discussions}

Figure 1 shows that there is a modest increase of $9.2 \%$ in the writing scores of the students after they have taken the course in the fall term, 1999. (In the spring term, the increase was $15.8 \%$ (See Endnote 5). Figure 2 shows that on average student perception of the level of difficulty of understanding the writing process, that of developing IT competence, of developing communication skills and teamwork has been lowered after attending the course. Figure 3 shows a similar result except in the category: Computer ethics as part of electronic literacies. At the end of the course students generally felt that ethical issues (like copyright, security, confidentiality, and integrity of information, etc.) were more difficult than they expected in the beginning. It seems that they have begun to appreciate the complexity of computer ethics like copyright issues, intellectual property rights, integrity of information, privacy, confidentiality and security. Understanding certain values is one thing, but practicing them is another. Our collective experience suggests that computer ethics as an essential part of electronic literacies is a big issue that has to be dealt with in greater depth. 
The major limitations of the research include the fact that the sample size is too small - only 17 students in the first term. There is only one set of data because it is the first trial run of the course. There are no control group and experimental group. Even if there were two groups, it is, in practice, almost impossible to find matched pairs of students of exactly the same writing proficiency at the start of the elective course. Students can pick and choose courses, but teachers cannot and should not pick and choose students.

The observation-participation of the course instructor prevents an entirely objective measurement of course effectiveness. Preliminary interpretations of the findings can only be made within a local context and situated practice with immersion in the experiment.

Another limitation is that writing is a complex activity of the mind, the body, and the use of writing tools (handwritten, typographic or electronic tools). It is easy to mistake the quantity of information for the quality of the experience. The final writing product can easily become more important than the process involved in creating it. The statistical data, numbers, and figures generated in the writing course do not necessarily reflect the quality of the experience the students gained in the interactive, communicative process. It is far too easy to over-simplify the complex writing activity and to make abstract, generalized claims out of the context. More research must be done to warrant any claim of generalizability. Relevant research questions include: How much time do students spend on learning English and how much on acquiring IT skills? How do you determine the exact causes of students' language improvement? IT tools? motivation? new learning environment?

An alternative to the quantitative analysis of the writing products is the qualitative approach using portfolio assessment and continued evaluation of the students' work.

The portfolio assessment takes more time, greater patience, and more experienced judgment on the part of the teacher. A student's portfolio is a collection, reflection, and selection of his or her writings produced throughout the term. It includes his or her essays, drafts, feedback from peers, e-mail exchanges and web pages produced by the group. It is often more instructive to listen to students' comments and let them speak for themselves.

\section{Students' comments}

The following comments are taken from students' writing portfolios and web sites: "This is an innovative project which integrates electronic collaboration and writing process with the Web. Though there are some imperfections, I appreciate the efforts of Mr. George Jor in making the new way of teaching and learning come alive. The experience gained from both the project and the course is invaluable to me. It prepares students for the information- and knowledge-based society."

- Simon Ng (Information Engineering major. Year 4)

\section{Success of the project}

"Experiencing online collaboration - The course succeeds in allowing students to collaborate in groups [with international students] with the aid of ICT.

Writing on the Web - The course requires students to build home pages. Students learn new text structure and are able to write on the Web.

Presenting information with skills - Students learn to present information with skills. 
The project not only benefits my learning, but also adds colour to my social life."

- Samantha Wong (Journalism major. Year 3)

"A number of characteristics of this course should be retained. The two-way communication between instructor and students allow the course to keep on improving. That made it different from traditional classes in which the communication is from the instructor to the students only. Moreover, the atmosphere of the class is very friendly and relaxing [partly] due to the sense of humor of the instructor, and the other part of the frequent discussion among all the classmates. And finally, the course web pages provides the students to read other's work and peer-review tasks can fully fulfill the goals of interactive learning. To conclude, the course inspires the creativity of students which is not easy to find in other classes."

- Melonie Chau (GPA major. Year 2)

\section{Gains from the project}

"Constructing our homepage is hard, but we have gained a lot of experience during the process. Second, the teamwork makes me more resilient.....

Third, I have built friendship with students abroad. Lastly, I am glad that I can share my experience with my partners in this project. I think this is the main objectives of our project and which has been reached."

- Nadia Leung (BBA major. Year 1)

\section{On peer-learning}

"It is true that doing technology is very much a social process. It takes time for people to find their roles and accept what is going to be changed. Therefore, I can imagine how difficult it has been for George with what he faced in the past few years. However, it is enjoyable and rewarding to have acceptance from peers. Since the most simple and direct way to learn and [to] teach is from peers who have shared the common background with you."

- Agnes Wong (JLM major. Year 3)

\section{A practical guide to electronic collaboration across cultures}

There are a number of lessons we have learnt in our electronic collaboration. We believe these 11 points might be helpful to the implementation of online collaborative projects.

- There must be advance planning among collaborating teachers.

- They must create situations and opportunities for students to interact and design the types of learning necessary for critical thinking, reading, and writing.

- There should be good matches in term dates.

- There must be engagement of students so that they become active learners and users of knowledge rather than passive receivers of knowledge.

- Collaborative learning is ideal for sharing information and interaction of minds. It has been said that "ICT is sharing of minds made visible."

- Collaborative learning can be very effective in developing judgment and problemsolving skills.

- It helps to use open-ended issues and problems. It encourages debates and creates rhetorical situations which force group members to negotiate solutions. That gives 
students practical experience in practicing negotiation, communication and persuasion.

- It creates personal knowledge through negotiation with language during social interaction. It is authentic, literary, interactive, and empowering.

- One of the most powerful ways to empower students is to give them ownership of their work and encourage them to take responsibility for their collaborative project.

- Electronic collaborative methods are, however, not suitable for all situations. It might not work as well as traditional presentational ways in teaching unfamiliar skills or concepts. It is not suitable for mechanical grammar drills.

- Education is a relationship. Technology is just a tool.

The LAB at Brown University and its associates have proposed a useful "eleven-step process" for implementing an online collaborative project. It is called "Electronic Collaboration: A Practical Guide for Educators" (June 1999). Naturally, one needs to think about the crucial factors of one's situation and adapt the step-by-step approach to suit one's own purposes. The goals of each individual project will determine what works best. I would like to summarize the 72-page Practical Guide for the reader's easy reference. What follows is a short summary of the "eleven-step process". Full details are available online at http://www.lab.brown.edu/

1. Determine your goals. Set the objectives according to class needs.

2. Decide when to start the project and think carefully about the guidelines for communicating. The ideal combination is a mixture of face-to-face meetings with online collaboration. The first one is face-to-face and the subsequent meetings are conducted online.

3. Decide how teachers will be compensated for their extra time.

4. Advocate strongly for your use of online conferences. Be prepared to meet negative responses with examples of successful collaborations by other groups.

5. Prepare a preliminary action plan or proposal that articulates your goals and lays out an initial timeline with specific benchmarks. It can serve as a starting point for discussions.

6. Decide what hardware and software are available, and in think terms of the existing infrastructure and financial implications for choosing a Web environment or just email.

7. Identify those you want to join the project and how you are going to invite participants. To identify potential collaborators for your project, the Practical Guide suggests mailing lists such as Reference.com -- http://www.reference.com/-- or the List of Lists. http://catalog.com/vivian/interest-group-search.html. E-mail and words of mouth can be helpful.

8. Select the participants and the facilitators.

9. Prepare for the first group encounter like a teachers' seminar. Let participants introduce themselves and discuss their expectation. Encourage them to inspect what they expect. Agree on common goals, common tasks and the common schedule.

10. Let the discussions begin! The facilitators can take the lead in raising questions, posing scenarios, and offering suggestions for strategies and activities. Once participants get comfortable with the technology, they will likely take a more active role in shaping the discussion.

11. Evaluate the project work. It should be an ongoing process to which all participants contribute. The coordinator can help guide this process by regularly asking the group about their progress. 
(Summarized from LAB at Brown University's Electronic Collaboration: Practical Guide for Educators, June, 1999).

\section{A call for participation in a Collaborative Writing Project 2000}

If our course objective of learning English writing and IT skills- "painting with two brushes at the same time" matches your class needs, you are invited to further explore possibilities of electronic collaboration with us in the fall term, 2000. You can find a workable prototype and proven collective experience of nine teachers, six schools and over 200 students on the Web. You are welcome to browse through our website, online resources and photos at URL:

http://humanum.arts.cuhk.edu.hk/ cmc/2002a/index.html

Your suggestions and advice are most welcome. Please contact the coordinator directly by the following address:

George C.K. Jor, The English Language Teaching Unit,

The Chinese University of Hong Kong, Shatin, N.T., Hong Kong.

Fax: (852)2603-5157 E-mail: george-jor@cuhk.edu.hk

\section{Conclusion}

It has been a great learning experience for us at CUHK and those who have taken part in the electronic collaboration across cultures. We have learnt a great deal from our partners. We look forward to more opportunities of electronic collaboration with partner classes in the process of interaction and inter-creativity beyond the classroom. William A. Ward once said, "The mediocre teacher tells. The good teacher explains. The superior teacher demonstrates. The great teacher inspires."[4] Our electronic collaboration has been an inspiring teacher to us all.

\section{Endnotes}

1. A famous Chinese saying in Chinese culture, it is taken from the Ming Collections of Famous Chinese Paintings. A rough translation of it in English is "killing two birds with one stone."

2. Details of the four schools in the collaborative writing project 1999 are available on the Web at URL:

http://humanum.arts.cuhk.edu.hk/ cmc/2002a/partners1999.html\#schools.

3. Details of the six schools in the collaborative writing project 2000 are available on the Web at URL:

http://humanum.arts.cuhk.edu.hk/ cmc/2002a/partners2000.html\#schools.

4. Progress Magazine, December 23, 1992.

5. Double marking scores of pre- and post-course writing samples in the spring term 2000

\begin{tabular}{|c|c|c|c|c|c|c|}
\hline Student & \multicolumn{2}{|c|}{ Marker One } & \multicolumn{2}{c|}{ Marker Two } & \multicolumn{2}{c|}{ Average Score } \\
\hline & Pre-test & Post-test & Pre-test & Post-test & Pre-test & Post-test \\
\hline
\end{tabular}




\begin{tabular}{|c|c|c|c|c|c|c|}
\hline 1 & 4 & 4 & 2 & 4 & 3.0 & 4.0 \\
\hline 2 & 3 & 3.5 & 3 & 3 & 3.0 & 3.3 \\
\hline 3 & 5 & 6 & 5 & 5 & 5.0 & 5.5 \\
\hline 4 & 3 & 3.5 & 3 & 4 & 3.0 & 3.8 \\
\hline 5 & 2 & missing & 2 & missing & 2.0 & 1 \\
\hline 6 & 4 & 3.5 & 4 & 2 & 4.0 & 2.8 \\
\hline 7 & 3 & 4 & 5 & 5 & 4.0 & 4.5 \\
\hline 8 & 4 & 4 & 5 & 4 & 4.5 & 4.0 \\
\hline 9 & 4 & 4.5 & 4 & 5 & 4.0 & 4.8 \\
\hline 10 & 5 & 5 & 5 & 5 & 5.0 & 5.0 \\
\hline 11 & 3 & 4 & 4 & 4 & 3.5 & 4.0 \\
\hline 12 & 6 & 5.5 & 6 & 6 & 6.0 & 5.8 \\
\hline 13 & 3.5 & 3.5 & 2 & 5 & 2.8 & 4.3 \\
\hline 14 & 3.5 & 4 & 3 & 6 & 3.3 & 5.0 \\
\hline 15 & 4 & 4.5 & 3 & 5 & 3.5 & 4.8 \\
\hline 16 & 4 & 4 & 4 & 6 & 4.0 & 5.0 \\
\hline 17 & 4 & 4 & 3 & 3 & 3.5 & 3.5 \\
\hline 18 & 4.5 & 5 & 3 & 3 & 3.8 & 4.0 \\
\hline 19 & 3 & 4 & 3 & 4 & 3.0 & 4.0 \\
\hline 20 & 4 & 5 & 4 & 5 & 4.0 & 5.0 \\
\hline 21 & 4.5 & 5 & 5 & 6 & 4.8 & 5.5 \\
\hline \multirow{2}{*}{\multicolumn{5}{|c|}{$\begin{aligned} \text { Average } \\
\text { Changes in scores before and after the course }\end{aligned}$}} & 3.8 & 4.4 \\
\hline & & & & & \multicolumn{2}{|c|}{$15.8 \%$ increase } \\
\hline
\end{tabular}

\section{Acknowledgements}

I would like to acknowledge the good advice and strong support of my partner teachers and advisors. They are Dr. Glenn Shive, Dr. Becky Nugent, and Dr. Todd Rohman of Governors State University; Dr. Nannette Smith and Stella Lee of Bennett College, North Carolina; Prof. Peiya Gu, and her MA students, Michelle Jin, Carol Yan, and Juliet Zhu of Soochow University, China; Dr. Anita Lie and Mr. Setefanus Suprajitno, Jenny MD of Petra Christian University, Indonesia, and my friend and former schoolmate, Mr. K.T. Li of Pui Ching Middle School, Hong Kong. My heartfelt thanks go to them and their students. It is a privilege. I enjoyed working with them and have learnt a great deal in the process.

\section{References}

Albom, M. (1999). Tuesdays with Morrie.: an old man, a young man, and life's greatest lesson. 3rd. Ed. London: Little, Brown and Company.

Berners-Lee, T. (1999). Weaving the Web: the original design and ultimate destiny of the World Wide Web by its inventor. New York: HarperCollins. 
Bond, M. (1999). "Using student-managed task groups to enhance learning." An unpublished speech delivered at the Teaching Cell organized by the Teaching Development Unit, of The Chinese University of Hong Kong on October 12, 1999.

Brooks, J.G. \& Brooks, H.G. (1993). In search of understanding: the case for constructivist classrooms. Alexandria, VA: Association for supervision and curriculum development.

The Chinese University of Hong Kong. (1999). Annual Report 1998-1999. Hong Kong: The Chinese University of Hong Kong. p. 58.

The Chinese University of Hong Kong. (1999). The Chinese University of Hong Kong Student Handbook 1999-2000. Hong Kong: The Chinese University of Hong Kong.p.58. (Available on the Internet at http://www.cuhk.edu.hk/adm/)

Duderstadt, J. (1999) "Can Colleges and Universities Survive in the Information Age?" Ed. Richard N. Katz and Associates. Dancing with the Devil: Information Technology and the New Competition in Higher Education (pp. 1-25). San Francisco, CA: Jossey-Bass.

"E-life: how the Internet is changing the world" Newsweek (October 11, 1999), 32-46. (A special report on the dawn of e-life).

Green, Kenneth C. (1998, November). The Campus computing project: The 1998 national survey of information technology in higher education [Online]. Encino, CA. Available URL http://www.campuscomputing.net/

Jor, C. K. (1999). "Web teaching in Hong Kong: a story". Ed. Sheldon, M., Rice, J., \& Lau, P. The Hong Kong-America Center Occasional Paper, No.13, 20-35. (A modified version is available on the Internet at http://humanum.arts.cuhk.edu.hk/ cmc/research/icted99.html)

. (1996). "Web newsletter '95: a collaborative learning project for technical writing instruction" In Mark Warchauer's Virtual Connections: On-line Activities and Projects for Networking Language Learner. National Foreign Language Resource Centre, University of Hawaii at Manoa, 268-74.

. (1995). "New ways of using the Internet to teach technical writing," Proceedings of the Tel.Ed'95- The Fourth International Conference on Telecommunications in Education. Tallahassee: ISTE and SouthEastern Regional Vision for Education, 121-123.

LAB at Brown University, et. al. (June 1999) "Electronic Collaboration: A Practical Guide for Educators" Providence, RI: Lab at Brown University. (More information are available on the Internet, URL: http://www.lab.edu/)

Leask, M. \& Pachler, N. (1999). Learning to teach using ICT in the secondary school. London: Routledge. 
Lewis, B. et. al. (2000). "Shaking the Tower: Technology, Education and Policy at the Dawn of the 21 Century." (A speech given by Prof. Brian Lewis of Simon Fraser University at The Chinese University of Hong Kong on March 21, 2000. It is based on their forthcoming book, Tower under siege: technology, policy and education, to be published by McGill-Queens in 2000).

Morall, A.(1999). "Teaching English by the Web: strengths, weaknesses, opportunities and threats". Ed. Sheldon, M., Rice, J., \& Lau, P. The Hong Kong-America Center Occasional Paper, No.13, 4-14. Also available on the Internet at URL http://elc.polyu.edu.hk/CILL/ICTED99/ICTED99Paper.htm

Nasbitt, J., Naisbitt, N. and Philips, D. (1999). High tech. High touch: Technology and our search for meaning. New York: Broadway books.

New London Group. (Spring, 1996). "A pedagogy of multiliteracies: designing social futures." Harvard Educational Review. Vol. 66. No. 1

Sandholtz, J.H., Ringstaff, C. and Dwyer, D.C. (1997). Teaching with technology: creating student-centered classrooms. New York: Teachers College, Columbia University.

Shive, G. (1999). "Collaborative learning across cultures via the Web. Ed. Sheldon, M., Rice, J., \& Lau, P. The Hong Kong-America Center Occasional Paper, No.13, 1519.

Teacher Enhancement Electronic Community Hall, et. al. (1999). Electronic collaboration: a practical guide for educators. Cambridge, MA: TERC.

Tyner, K. (1999). Literacy in a digital world: teaching and learning in the age of information. New Jersey: Lawrence Erlbaum Associates.

Warschauer, M. (1995). E-mail for English Teaching. Alexandria, VA: TESOL. . (1999). Electronic literacies: language, culture, and power in online education. New Jersey: Lawrence Erlbaum Associates.

. (2000). Internet for English Teaching (forthcoming. It will be published by TESOL). 